\title{
"I'm Bart Simpson, who the hell are you?" A Study in Postmodern Identity (Re)Construction
}

\author{
B R I A N L. OT T
}

Performance - The semiotics of self. (O'Sullivan et al. 222)

I AM SITTING AT MY COMPUTER MULLING OVER THE THREE OR FOUR acceptable conventions for beginning a scholarly article under the watchful eye of my Bart Simpson doll perched amid my media theory books on the shelf just above me. I carefully reach for the bright yellow and blue plastic toy - a gift from an old friend, former colleague, and fellow Simpson fanatic several years ago-and gently tug at the tiny white cord protruding from its back. Without hesitation, Bart comes alive, impertinently inquiring, "I'm Bart Simpson, who the hell are you?" At the request of this great cultural icon and postmodern philosopher, I pause to consider who the hell I am, and what, if anything, it has to do with the doll I now hold in my hands.

We are frequently, of course, told in a media-laden landscape that identity is closely tied to the active consumption of products offered by the media and leisure industries (Kellner 231-62; Featherstone). That I proudly display the Bart doll in my office, along with a host of other Simpson-related merchandise, does seem to suggest that I desire others to read and mark me as a Simpson fan. Continuing to reflect on my sense of self, I decide that the form of Bart's question, like the doll itself, is also instructive, as it alludes to a fundamental feature of

The Journal of Popular Culture, Vol. 37, No. 1, 2003

(C) 2003 Blackwell Publishing, 350 Main Street, Malden, MA 02148, USA, and PO Box 1354, 9600 Garsington Road, Oxford OX4 2DQ, UK 
identity construction and maintenance: difference. Explain Morley and Robins, "identity must be defined, not by its positive content, but always by its relation to, and differentiation from, other [identities]" ("Spaces" 10), and thus "difference is constitutive of identity" (Spaces 45). "I'm Bart Simpson, who the hell are you?" functions rhetorically to delimit Bart's identity through reference to a non-Bart. But just how are these differences - these boundaries - established? Media scholars argue that the sociocultural factors and forces, which structure difference and subsequently create the boundaries essential to identity, have changed dramatically in recent decades (Kellner 231-62; Rosenau 42-61; van Poecke 183-84). Historian Mark Poster claims, "a postmodern society is emerging which nurtures forms of identity different from, even opposite to those of modernity" (24).

Fordist modernism - with its "stable, standardized, and homogenous markets, [its]... easily identifiable authority and metatheories, secure grounding in materiality and technical-scientific rationality" (Harvey 338-39) - gave way to the rational individual in which identity arose from faith in a circumscribed set of roles and norms within a community or nation state. In modernist terms, describes Kellner, "one is a mother, a son, a Texan, a Scot, a professor, a socialist, a Catholic, a lesbian - or rather a combination of these social roles and possibilities. Identities are thus still relatively fixed and limited, though the boundaries of possible identities, of new identities, are continually expanding" (231). But as the economic mode shifts from a goods-based model to a service-based one, from centralized mass production to transnational, global culture industries, subjects are less able to locate their identities in pre-given categories and ascribed roles. "So, class, gender and ethnicity, decline in social significance" (Crook et al. 35), while the active consumption of images and styles grows in importance (Kellner 231-62; Rosenau 42-61; van Poecke 183-84). Difference - and subsequently, identity — is now defined and affirmed through consumer choice.

Though generally I am compelled by the theoretical claims surrounding this apparent shift, I wish in this article to problematize and then clarify those claims in an important way. Efforts to theorize shifting conceptions of identity have preceded largely without, in Kellner's words, "systematic and sustained examination of the actual texts and practices of popular media culture" (234). Indeed, van Poecke's essay, one of the most sophisticated treatments of this subject, makes not a 
single reference to a specific media text. Consequently, much of the existing literature regarding postmodern identity represents the break from modernist notions far too cleanly, and in a manner that does not adequately reflect the lived experiences of present-day subjects. The hope is that by studying a specific case, the theory can be refined so as to better assist people in negotiating their rhetorical environments.

To accomplish this aim, this article undertakes an analysis of the Fox network's thirty-minute, award-winning animated series, The Simpsons, ${ }^{1}$ and the characters of Bart, Homer, and Lisa. The culture industry, and television in particular, performs two functions with regard to identity formation today. First, television furnishes consumers with explicit identity models, models not of who to be but how to be. Viewers learn to fashion their identities by watching popular characters fashion theirs (Kellner 238-47). Second, television furnishes consumers with the symbolic resources - the actual cultural bricks - with which to (re)construct identity. Viewers continuously construct and deconstruct their identities from those bricks. Thus, television both shapes the nature of identity by providing identity models and provides the symbolic resources for enactment. These two functions serve, then, as the general organizational scheme for this article. In the first major section, I argue that Bart, Homer, and Lisa demonstrate distinctive, though not exclusive, models of identity. These models serve only as guideposts and viewers often perform their identities in ways that creatively combine differing models. In section two, I contend that consumers find a variety of symbolic resources for enacting the identity modes modeled in the series. But first, I comment on The Simpsons's history, status, and importance as a cultural text.

\section{The Anti-Show Show}

Now in its twelfth season, The Simpsons is "the best TV show ever" (Poniewozik 73). With that sentence I have, no doubt, immediately divided my audience. Fans of the series recognize that such an obvious value-laden statement is intended playfully, that it draws attention to the formal requirements of academic writing even as it violates them, and that it enacts the principles that underlie the Fox network's longrunning hit series. Writes poet laureate Robert Pinsky, "The Simpsons teases its form, and cavorts inventively within that form .... [It] achieves excellence by playing with the nature and history of 
television" (12). Non-fans and those committed to policing academic writing conventions are wholly unimpressed by my self-reflexivity around this point, believe "play" has no place in scholarship and that, as a colleague recently reminded me, "crap like this undermines the entire discipline and is slowly leading to its demise." In other words, they don't get it.

The tension between getting it and not getting it lies at the heart of why The Simpsons is such a significant cultural artifact of the 1990s. From its inception as an animated-short on the Tracey Ullman Show in 1988 to its current twelve-year stint as the longest-running primetime animated series in television history, The Simpsons has always represented a sort of anti-show, spoofing, challenging, and collapsing the traditional codes, structures, and formulas of network television. In fact, its parent network, Fox, which owes a great deal of its success to the series, was itself the marker of a new age in television. According to Herron, "[W] ith the average prime-time share [of network TV] dropping from 93 percent in the 1976-77 season to 62 percent in 1992-93 . . . , [the fledgling Fox network] found its audience by making shows that precisely implicated that status of representation as such" (16). For many viewers raised in an image-saturated culture and attuned to the well-worn formulas of television, shows that were silent about their status as representations came to be seen as fake and simpleminded, while shows that reveled in their fakery seemed somehow more real and sophisticated (Pinsky, "Creating" 17).

Nowhere was this shifting sense of taste demonstrated more clearly than in the coterminous rise of The Simpsons and decline of The Cosby Show. In August 1990, Fox moved its new hit series from Sunday nights to Thursday nights opposite NBC's The Cosby Show, which just a season earlier had finished in the Nielsen ratings as the number two top-rated series (McNeil 1159). The Simpson family quickly became television's leading anti-family (Zoglin 85); utterly dysfunctional, they mocked TV's idealistic families of early decades, its nostalgic throwbacks of the 1980s, and its convenient, simplistic resolution of narrative conflicts. The juxtaposition was stark and accentuated just how impoverished the images of the Cosby family were. As sociologist Todd Gitlin is quoted as saying, "[it was] becoming harder to get an audience to believe in family fairyland" (Elm 8). By the 1991-92 season, The Cosby Show had slid to sixteenth in the ratings, where the show ended its eight-year run. Meanwhile, the Simpsons were being touted as "the typical American 
family" (Rebeck 622), a viewpoint that had many educators, moral leaders, and politicians strongly denouncing it. ${ }^{2}$ The most infamous rebuke came from President George Bush in 1992; speaking at a convention of religious broadcasters, he decried, "We need a nation closer to the Waltons than the Simpsons" (Pinsky, "The Moral" 13-I). ${ }^{3}$ What Mr. Bush and other critics failed to understand was that, for many viewers, the Waltons of the 1970s and Cosbys of the 1980s simply no longer possessed any fidelity; they no longer accurately reflected reality. The Simpsons, by contrast, made no claims to represent an external reality; it changed the protocols of reading and in the process challenged the difference between image and reality altogether.

Few shows today are more reflexively fake - self-aware of their status as images and representations for which there is no external reality - than The Simpsons. The characters are, after all, cartoons, and crudely drawn ones at that. The show's creator, Matt Groening, claims to have colored the characters bright yellow "because it made it look as if the TV needed adjusting" (Billen 50). It is this flaunting of television's flat, fabricated nature, of the show's candid artificiality that has prompted critics, from its debut to the present, to describe the Simpsons as "the only real people of TV" (Zehme 41) and "thoroughly human in our minds" (Mink 102). The Simpsons is hyperreal; it gestures first and foremost to itself, creating a semiotic circularity that imbues images with their own veracity and truth (Baudrillard, Simulations). It is within a logic, where the image of Bart Simpson refers only to Bart Simpson the image, that TIME magazine can crown Bart as one of the twenty most important entertainers of the twentieth century (Corliss 204), that Adweek magazine can name Homer best celebrity spokesperson, that Ms. Magazine can feature Lisa on a cover dedicated to the "Many Faces of Feminism" (Borrelli n. pag.), that Entertainment Weekly can rate the Simpsons among the top ten greatest entertainers of all time (Snierson), and that the Simpsons can earn their own star on the Hollywood Walk of Fame (Bianculli, "Hurray" 46). Each week, The Simpsons reminds viewers that appearance is reality.

\section{Modeling Identity: Bart, Homer, and Lisa}

The notion that television is a powerful socializing agent in contemporary culture is repeated with such frequency by both academics and the media itself that the assumptions at its core are 
rarely interrogated. Despite the impressive body of literature regarding audience activity (Croteau and Hoynes 261-94), especially as it relates to interpretive communities (Fish 465-85), the socializing effects of television are still treated as relatively homogenous. It is assumed, for instance, that television in general and specific shows in particular socialize viewers to make sense of their world and themselves in uniform ways. But I want to suggest that because viewers come to TV with unique experiences and interpretive strategies, they leave with different sets of meaning as well. To the extent that Bart, Homer, and Lisa are all characters on the same series, there are undoubtedly points of intersection and commonality between them. The Simpsons is often regarded as the quintessential postmodern television series of the 1990s (Campbell and Freed 75), and thus it is likely that Bart, Homer, and Lisa would reflect/enact a postmodern model of identity. But the characters are also very different and invite identification with different viewers, and subsequently offer not a singular model of postmodern identity, but plural models of postmodern identity.

Bart, Homer, and Lisa teach viewers lessons about selfhood - about how it is created and maintained-and this section explores the similarities and differences offered by those lessons. The Simpsons is especially well suited for such an investigation because it appeals to a diverse audience. "One major miracle of The Simpsons," writes Bianculli, "[is that] it entertains several generations simultaneously" (Dictionary 294). Since its 1990 premier, the show has consistently attracted gradeschoolers, Gen-Xers, and adults alike (Erickson 451; Owen 64; McNeil 756). Billen notes that, "Children identify with the brattish ten-yearold, Bart" (49), while adults tend, on the other hand, to identify more with "Bart's loafish father - the cowardly, incompetent, deluded, greedy consumer of the American Dream, Homer Simpson" (49). But age does not begin to tell the whole story. "According to Fox Television, 6 million of the show's 15.4 million weekly viewers are women .... [and] The Simpsons is one of the few TV shows watched in large numbers by whites, African-Americans, and Hispanics" (Borrelli n. pag.).

So, just who are the Simpsons? They are characters on television, but they are not characters in a traditional television sense. As cartoons, the characters are not "played" by actors and subsequently they exist only as images. Bart is a ten-year-old rebel, proud underachiever, video-game enthusiast, Krusty the Clown fan, and television junkie. 
Homer is a dull-witted husband, father of three, incompetent nuclear safety inspector, and beer-drinking couch potato. Lisa is an eight-yearold genius, feminist, vegetarian, musician, and moral center. Strip away the images that define them and Bart, Homer, and Lisa cease to exist. But strip away the images of the fictional character Buffy on Buffy the Vampire Slayer and actress Sarah Michelle Gellar (who bears a striking resemblance to Buffy) remains. Though Buffy's identity is clearly image-based, it is not free from Sarah Michelle Gellar. Indeed, it is Sarah Michelle Gellar, not Buffy, who is invited to appear on TV talk shows and may one day earn her own star on the Hollywood Walk of Fame. ${ }^{4}$ So, whereas Buffy's identity will always bear the traces of someone other than herself (i.e., Ms. Gellar is not a superhuman demon ass-kicker), the Simpsons' identities bear no such deceptive traces at all. That Bart, Homer, and Lisa are themselves the real thing (i.e., authentic) allows for a unique flexibility in identity.

Bart's identity, for instance, is located less than Buffy's in traditional, modernist categories associated with the physical body. Bart's sex, for instance, is not as central to who he is as is Buffy's, which may explain why both male and female youth identify with Bart. In 1999, when Children Now, a national child advocacy organization, asked a national sampling of boys and girls ages 10-17 to identify their top television role models, Bart Simpson finished second among the boys and fourth among the girls (Huff 130). In appearance, Bart resembles neither a young boy nor a young girl, and his voice, which is performed by Nancy Cartwright, allows for still further genderbending. From his bulbous eyes and yellow tint to his simple and permanent attire, it is difficult to imagine that anyone identifies with Bart's appearance. Though he does not lack gender, it is not as determinative of his identity as the other images that coalesce around him. The distinctions between Bart and Buffy are significant because they highlight that identity today has not simply transformed the modern individual into the postmodern personae. They indicate a range of spaces between the outward projection of a relatively stable and essential self, grounded in inherited and pre-given categories, and the performance of a flexible and radically under-determined self, located in images and styles.

Bart is above all a rebel, or at least a compilation of rebellious images (Conrad 75). His rebel status is heavily coded through his leisure activities, which for Bart are pretty much all of his activities. 
Typical of the postmodern subject for whom "everything that he/she does must be pleasurable" (van Poecke 194), even at school, Bart plays the class clown, blurring the line between work and entertainment. Perpetually in trouble with his teachers and Principal Skinner, each episode of The Simpsons begins with Bart at the blackboard scribbling his latest wrongdoing. When not in school, Bart spends most of his time skateboarding and watching his favorite TV program. The skateboard - perhaps the most celebrated symbol of Generation-X (Rushkoff 28-34) - or more appropriately, Bart's appropriation of the skateboard, allows Bart to mark himself as independent, free-spirited, and anti-authoritarian. But it does not overdetermine him, as Bart simultaneously shuns the image of drugs frequently associated with skateboarding. Bart seizes the skateboard image and (re)codes it to suit his purposes/identity.

Bart's idol and role model, Krusty the Clown, who is the star of a local children's television program, is also important to his identity. ${ }^{5}$ Frequently at odds with law enforcement (i.e., the adult equivalent of authority), Krusty provides yet another countercultural image for Bart to appropriate and mold as part of his being. Bart faithfully and fanatically watches Krusty's show, intimately educates himself about its production history, and purchases every imaginable item of Krusty merchandise, from the Krusty poster and pajamas to his lunchbox and walkie-talkies. ${ }^{6}$ Bart cannot simply be reduced to the figure of Krusty, though, as his appropriations are strategic and selective. Bart has no desire to become Krusty, only to share Krusty features. As a fan, Bart shapes his identity without turning it over to the culture industries. Krusty is also a noteworthy model because when he washes off his make-up, he still resembles a clown, suggesting that no distinction exists between the character he plays and his actual identity. Likewise, Bart's identity exists only in his tireless performance of images acquired from the culture industries. As will become evident in the next section, Bart's outward performance of his rebellious identity through phrases such as "Eat my shorts!" and "Don't have a cow, man!" are the very images of Bart that fans seize to manufacture their own identities.

Not all child television characters model identities as disembodied as Bart's. Mary-Kate and Ashley Olsen, the twin stars who gained fame as Michelle on Full House before releasing a long line of straight-tovideo motion pictures in which they play themselves, mark their identities through fashion and style. Like Bart, the Olsen twins are 
forever performing their identities, but the images upon which they draw are rooted in the glamour industries. In contrast to Bart, they teach viewers that one is what one wears, and hence they have their own line of fashions at Wal-Mart and offer daily, cool "fash" tips on their Web site. Bart's brand of identity, which features attitude over (physical) appearance, is simply one variation on a postmodern theme then. And it is one that appeals to cyberpunks, who live much of their lives in an online environment where the physical body is quickly evacuated (Turkle 177-86). For many cyberpunks, especially hackers, echoes of Bart are obvious. Hackers surf the Internet, often passing through private systems and networks the way Bart travels sidewalks and slashes through neighborhoods on his skateboard. Their very presence and movement signify rebellion and disruption. Hackers continually create designer identities and fashion themselves as selfreliant, self-thinking, countercultural innovators (Leary 364-72). Cyberspace, then, affords a terrain where Bart's brand of identity can be and is being realized, where formal education and the body are not as crucial to one's sense of self-worth as are one's unique skills and knowledge, one's ability to "make do" in a system that is always against.

While Bart is always rebelling against the system, seeking to exploit its cracks, and "holding a 'be-yourself' attitude" (Rosenau 53), Homer is the classic dupe. He is produced/used by the system he cannot resist - a product of his own conspicuous consumption. Though he is a safety inspector at the nuclear power plant and a father and husband, Homer's identity emerges as a consequence of his hedonistic consumption of beer, television, and food (Halwani 10-11). In modern terms, occupation was central to identity; one was largely what one did - a farmer, coal miner, teacher, and so on. The increasing specialization and subsequent fragmenting of the workforce, however, make occupation a poor signifier of self. Nuclear safety inspector is only one of thousands of high-tech jobs in a service-based economy, and therefore lacks shared semiotic currency. The relative insignificance of Homer's job to his identity is clear at the level of representation: (1) Homer never loses his job, despite frequent and utter incompetence (\#8F04, \#4F19); (2) Homer is rarely seen doing his job, and when he is, his main responsibilities include "snack machine monitoring, clock watching, inner-eyelid study and pastry malfunction prevention"; and (3) Homer spends significantly more (representational) time within the 
series at Moe's Tavern than at the nuclear power plant. This suggests that nuclear safety inspector is not nearly as central to who Homer is as is his favorite brand of beer, the much-marketed Duff - and indeed, whole episodes have been based around his Duff obsession (\#9F14).

Homer's favorite activity, next to drinking beer at Moe's, is watching television, which he does indiscriminately. In fact, he is so intoxicated/obsessed with television that he has worn a self-conforming groove into the family's couch, and frequently cannot distinguish real life from television's images. In one episode (\#2F06), Homer begins to believe he is guilty of a crime that he did not commit because he sees it on television; questioning his own innocence, he laments, "Oh, may be TV is right. TV's always right." Far from shedding light on reality, television and its excess of information and images foster, in Baudrillard's terms, "loss of scene" ("The Masses" 101). Homer is, in a sense, overinformed by TV. Such blind and bottomless consumption extends to his eating habits as well. Thus, the physical body that Bart so quickly and consistently eschews returns with an increased weight in the character of Homer. There is practically nothing that he will not eat, including a ten-pound bag of flour (\#9F06), sixty-four slices of American cheese (\#1F01), and two buckets of bad prawns (\#1F10). At least four episodes (\#7F11, \#9F06, \#3F24, \#AABF13) concern his food obsession. Homer's obese body codes him as obscene, as lacking perspective, as unable to exercise any consumptive restraint. His whole identity, then, resides in his endless consumer practices-drinking Duff, eating doughnuts, watching television-without which he is reduced to the now vacuous categories of father and husband. I say vacuous because they are secondary to Homer's practices of consumption, a point not lost on Bart, who shares with Homer, "It's just hard not to listen to TV. It's spent so much more time raising us than you have" (\#2F06).

At age thirty-six, one might expect to better understand who Homer is by looking at his past, but history for Homer is no less based in consumption and the culture industries than the present. Homer rejects the modernist notion that identity is "the influence of infancy, ... . the Freudian concept of the unconscious (drive theory, for example), and the idea that actions of the self may represent severe forms of internal psychological conflict whose origins lie in primitive emotional symbolization" (Glass 256). His past is merely a collection of nostalgic images from TV's past, and consequently, flashbacks to his 
past are frequently predicated on some present-day crisis with the TV set; either it breaks (\#7F12) or Marge insists that it be turned off (\#2F10). During one flashback episode (\#9F21), viewers learn that Homer was once part of a Grammy-winning barbershop quartet, an experience that turns out to be nothing more than a series of nostalgic gestures to the rise and fall of the Beatles (Shales B1). That Homer's past is often inconsistent with his present life is inconsequential, because it is simply a vehicle for a trip down media lane, not a psychological clue (i.e., structuring element) to who he is today.

Even Homer's present self is often inconsistent with his present, having variously become a NASA astronaut (\#1F13) and an unwitting assistant to super-terrorist Scorpio in his plot to take over the world (\#3F23). In these episodes, Homer's identity is (re)produced (i.e., scripted) by images from The Right Stuff and James Bond films, as opposed to being anchored in history. Since, as a cartoon, he never ages and therefore never "grows" psychologically, and since he has no real history, Homer can be radically multiple and contradictory. One week he can be a monorail operator (\#9F10) and the next a cannonball target in the traveling freak show (\#3F21). Homer, it could be said, "lives not in history, but in a transhistorical space of images lacking any inherent psychological or affective connection" (Glass 275). Having no base to return to, Homer models a radically decentered subject who appears to be simply another product of the culture industries. No matter how traumatic his experiences, Homer never learns anything, in part, because he is not a distinct, thinking subject.

Homer and Bart's identities bear a different relation to the image culture - the excess of signs - upon which they both rely. Unlike Bart, who selectively appropriates the culture industries' images to mold his identity, Homer is hopelessly manipulated by television. Bart skates around the edges of the media landscape, stealing image fragments along the way from which to stage a coherent, if mutable, identity, without ever fully being immersed in the landscape. Homer, by contrast, is the landscape; he is anything and everything churned out by the culture industries. He furnishes a vehicle for endless intertextual reference and exemplifies a radical postmodern multiplicity - "an extreme rejection of boundary, stability, historicity, and any concept of a cohesive self" (Glass 276). In essence, Homer models an anti-identity; his being critiques the modernist idea of a unified, coherent subject. It implodes the entire subject-object dichotomy, which assumes the 
subject can attribute meaning, seize power, and influence others (Rosenau 42). Homer is ultimately incapable of influencing an external reality, because for him there is no external and no real.

Unlike Homer, who lacks subjectivity and hence any politics, Lisa is an active agent who learns from her experiences, believes in the ideal of progress, acts in accordance with her beliefs, and is intensely committed to the "projects" of feminism, vegetarianism, and environmentalism. The many "isms" to which Lisa dedicates herself are teleological; they assume that signifiers construct identifiable and relatively stable boundaries. They rely upon symbolic structures and chains of meaning that provide the basis for critique and evaluative judgment of the social world. But how is it that a media text can, at once, furnish the "grounds" upon which Lisa's identity grows and dissolve any grounding that would allow Homer to be an agent? The answer has to do with a frequently ignored distinction in the manner (i.e., the form) that The Simpsons presents Homer and Lisa. The "stories" that focus on Homer are scarcely stories at all; Homer is chiefly a vehicle for intertextual allusion and rarely, if ever, is an event involving Homer a logical, necessary, or even related outcome to a prior event or experience. Writes Kellner, "the signifier has been liberated and the image takes precedence over narrative, as compelling and highly artificial aesthetic images detach themselves from the television diegesis and become the center of fascination, of seductive pleasure, of an intense but fragmentary and transitory aesthetic experience" (235-36). Where Lisa is concerned, however, narrative remains central. In form, narratives unfold, establishing conclusions that "build upon" what is sequentially prior (Gergen n. pag.). Episodes that focus on Lisa- "Lisa the Beauty Queen" (\#9F02), "Lisa the Vegetarian" (\#3F03), "Lisa the Iconoclast" (3F13), "Lisa the Skeptic" (\#5F05), "Lisa the Simpson" (\#4F24) - are, as the titles suggest, narrative explorations of her identity. In recounting her experiences-what she learns from those experiences and how she acts on those experiences toward political ends - such episodes narrate Lisa's identity.

One of the clearest examples of this process occurs in the episode, "Lisa vs. Malibu Stacy" (\#1F12), in which Lisa wages a crusade to counter sexism in popular culture after she purchases a talking Malibu Stacy doll and discovers "that the doll can only utter vacuous phrases that reinforce sexist stereotypes" (Richmond and Coffman 135), such as, "I wish they taught shopping in school" and "Don't ask me-I'm 
just a girl [Stacy giggles]." Fearing that, as she tells Bart, "Millions of girls will grow up thinking that this is the right way to act - that they can never be more than vacuous ninnies whose only goal is to look pretty," Lisa convinces the doll's creator, Ms. Lovell, to produce a new doll that embodies the qualities she respects, one that has "the wisdom of Gertrude Stein and the wit of Cathy Guisewite, the tenacity of Nina Totenberg and the common sense of Elizabeth Cady Stanton. And to top it off, the down-to-earth good looks of Eleanor Roosevelt." The story then traces Lisa's battle with the big toy companies to get her doll, Lisa Lionheart, produced. Though in the end the doll flops, "Lisa concludes that even if her doll makes an impression on just one little girl, her efforts have been worthwhile" (Richmond and Coffman 135). That the Lionheart doll is a marketing failure is ultimately not as important to Lisa's identity as is the rhetorical device of narrative. Notes Esders, "the conceptual components of narrative-character, causality, intelligibility, credibility - bestow identity on individuals" (77). Lisa's identity emerges across this and other episodes that tell Lisa stories, stories that simultaneously reveal and construct her values and beliefs.

\section{Scrapping Identity: Finding Symbolic Resources in Television}

The subheading for this section is intentionally multicoded to capture the variety of ways identity is performed. Scrapping identity can refer to a process of selectively piecing together identity from the image scraps of culture. This, the Bartesian model, requires individuals to remain a level removed from the images and styles upon which they draw in (re)shaping a sense of self. Scrapping identity can also refer to the throwing away of individualized identity in favor of the instant gratification offered by the culture industries. This, the Homeric model, signifies the loss of self in the endlessly expanding matrix of cultural production and replaces it with the pleasure of consumption. Or scrapping identity may refer to compiling key experiences and memories into a story (i.e., scrapbook) that narrates values and beliefs. This, the Lisaphonic model, rejects the deconstruction of all meaning in favor of notions of progress and commitment. In this section, I 
investigate how The Simpsons provides viewers with the symbolic resources to enact the various modes of identity modeled on the series.

The Bartesian model is enticing/useful to persons who see themselves as "hip to the formulas and gimmicks of media culture," and as "sophisticated and self-conscious consumers." Aware of their constant coding within a mediated landscape (i.e., the way they are defined/structured by the culture industries), they continuously seek to subvert the homogenizing nature of cultural products by selectively recombining them into new styles and images. Indeed, the whole notion of "self-awareness" implies separation/distinction from the vast array of signs circulating within the culture industries. It is this distinction that fuels the belief that one can exercise some degree of mastery over the sign. Following Bart's lead, viewers craft their identities through strategic purchases. One becomes, in part, what one buys. Since Bart is not rebelling against anything in particular, he represents rebellion in general. Therefore, through Bart-related merchandise (i.e., clothing, games, videos, and toys) one can purchase the image of rebellion.

Bart's use-value in constructing an oppositional identity is so great that T-shirts sporting slogans such as, "Don't have a cow, man!" and "Underachiever, and proud of it" were banned in many grade schools shortly after the show's premiere (Rebeck 622). "Because Bart's politics are purely oppositional," Herron argues that, "he provides a powerful and immediately recognizable site for staging difference. He has no history to bind him to a particular race or class or ethnicity, so he is semiotically up for grabs, and up for grabbing the opportunities that await us all" (19). As such, "Black Bart" - a black face version of the cartoon - was pirated almost instantaneously by segments of the African-American community, and a plaster Bart wearing a poncho appeared as part of a resistive, performance art piece, "The Temple of Confessions" (Gomez-Pena and Sifuentes 19).

Part of the reason Bart is so easily appropriated for use in creating an oppositional identity is that his identity privileges image over narrative. In contrast to Lisa, Bart has no political commitments and subsequently he can stand against anything. Bart offers a prepackaged image of rebellion, an identity largely independent of the show's weekly narratives. In fact, many Simpson fans purchase Bart-related toys and never unwrap them, because one marks one's identity as oppositional not by playing with Simpson toys, but by buying and 
displaying them. The danger of removing Bart-related merchandise from its precious mint packaging is that its interaction with other signs potentially re-codes and diminishes its resistive quality. The toys of modernism - its generic dolls and trucks - demanded interaction with their owners, who in supplying a context invested them with meaning. But the toys of postmodernism, with their cross-promotional media tie-ins, are predigested, precontextualized, and preplayed with - their meaning already encoded by their circulation in the culture industries.

Merchandise is not the only or even the primary way that persons construct an identity in relation to televisual images, however. As part of a vast informational economy, "The Simpsons has exchange value" (Herron 19), and thus one becomes in part what one knows. The endless intertextual gestures that animate the series each week function as a sort of quiz, testing viewer knowledge of both high and popular cultural texts (Ott and Walter 436). Within minutes of a new episode, the most dedicated fans gather online to share their observations. "[But at] any given time," writes Kanaley, "about 500 active discussion topics, or 'threads,' are listed in The Simpsons newsgroup called alt.tv.simpsons" (F1). Participation in online communities allows persons to define their identities, as they always have, relative to collectives. In modern terms, community was closely tied to geographic boundaries such as state and nation, but in a global electronic landscape, community is grounded in shared interests often generated by media culture (Vitanza 60-62). In twelve seasons, viewers still do not know where Bart Simpson lives because whether he lives in Texas or Maine is far less important to who he is than his being a Krusty fan. Today, being a fan of a television show or even a particular TV character invites a communal association and hence serves as a marker of identity.

To what extent Bart fandom codes one's identity is a product of just how much one knows about Bart. Indeed, The Simpsons is a multilayered text that quickly separates viewers into distinct categories of fandom. Regular or casual viewers would be able to identify the central characters, but would likely not "get" a large number of selfreflexive gestures in the series. ${ }^{7}$ Bart frequently comments, for instance, on rumors about himself or the show in the popular press - statements that would require specialized knowledge of the show's production history or studio publicity to be appreciated fully. Since within an 
informational economy, knowledge equals prestige, "there is a compulsion to be the first to circulate new information and to be among the first to possess it" (Jenkins 59). Thus, the show's most serious or obsessed fans scour individual episodes looking for obscure references or tracking and recording minutiae, such as intertextual movie references, previous episode references, and animation and continuity goofs. The transition from casual viewer to obsessed or obscene viewer reflects the identity differences modeled by Bart and Homer. Casual viewers steal from The Simpsons as well as other media texts to mold unique identities - a collage of their favorite media styles and images. As their tastes change, so too do their identities.

Obsessed viewers are no longer marking their identities through the series as much as they are losing their identities in the series. Indeed, the obsession of these "true" fans is well known to the show's producers, who frequently go out of their way to structure subtle jokes and messages into individual episodes - messages that can be seen only by recording the show and (re)viewing it frame by frame on a VCR. ${ }^{8}$ Since identifying obscure references promises greater personal reward and validation, the show invites obsessed viewers not only to watch it, but also to study it intently. In 2000, Fox executives reinforced this practice with the release of The Simpsons Trivia Game, whose packaging reads,

Hey Man, Bart Simpson here! Everybody knows that I'm America's bad boy, but do you know how many spikes I have on my head? Or what my geeky sister Lisa's middle name is? No? Well, don't have a cow, man! (The answers are below!) Inside this box are lots more questions about your favorite dysfunctional family, The Simpsons. You can compete with your friends, or even other Simpson trivianerds! See who knows more useless Simpson details and totally unimportant factoids!

As the packaging itself suggests, the endless consumption of Simpsons trivia does not create a more informed viewer who can then act in the world; it simply supplies instant gratification by creating pleasure in the consumption of the text. Some Simpson fans enact a Homeric model of identity in which subjectivity is secondary to the pleasure of consuming. Pleasure replaces subjectivity, because as the text is endlessly mined for more and more information, it carries less and less significa(tion)nce (Heim 10). 
While some viewers emulate Homer, becoming intoxicated with consumption, others learn from him. For viewers who feel overwhelmed by the excess of information and the new technologies animating it, Homer offers resolution through victimage (Brummett, Rhetoric 134). He, like most of culture's inhabitants, is guilty of overconsumption, of consuming exclusively for pleasure rather than need. Homer, then, is more than a cartoon character; he is a symbol of a shared guilt and a comedic tool for coming to terms with it. Comedy teaches the fool and hence the audience, explains Brummett, "about error so that it may be corrected rather than punished. Comedy does this through dramatic irony, in which audience members are placed in a position where they see behind the facade of the sins and errors that bedevil the fool" ("Burkean" 219-20). By the end of each episode, Homer is publicly embarrassed for his consumptive practices, thereby revealing the error of his ways and reintegrating him into the social hierarchy. Through the comic fool, viewers are shown the error of their ways, and chastened not to consume blindly, but to use the culture industries as Bart does - strategically. The Simpsons reflects an odd tension concerning consumption, then. It intoxicates some viewers by providing a multilayered text that promises pleasure in its endless consumption, as it simultaneously teaches other viewers to be wary of such action. It depends what relation viewers adopt to the images that surround them. Do the images offer boundaries for coding the self? Or do the images become a landscape where the self is but a fiction?

Image-based identities do not tell the whole story of contemporary notions of selfhood. For instance, Lisa Simpson's identity emerges primarily through storytelling. Though she does not narrate her own identity (i.e., the stories are told about her, not by her), she demonstrates how the form and features of narrative can be employed to craft a unified and autonomous self. "In late modernity, selfnarratives, autobiographical accounts, personal histories, and anecdotes," Esders argues, "are becoming more and more important in the construction and reconstruction of a personal identity" (76-77). To maintain the impression of fidelity, narratives are always selective and sutured. They create the appearance of coherency through the inclusion of some events and experiences and exclusion of others, and through their sequencing of elements.

"[A]utobiographical narrative is always," writes Bourdieu, "motivated by a concern to give meaning, to rationalize, to show inherent 
logic, both for the past and for the future, to make consistent and constant, through the creation of intelligible relationships, like that of cause (immediate or final) and effect between successive states, which are thus turned into steps of a necessary development" (298). In this mode, identity is a narrative "project" - "a trajectory of development" (Giddens 75) - that "builds upon what we think we are now in light of our past and present circumstances, together with what we think we would like to be" (Barker 167). The narrative construction of a coherent self is a discursive construction, an illusion, an appearance that is the self.

But Lisa does more than "model" narrative-based identity, she provides a conversation piece to build upon. Sands contends that, "identity is an evolving construction that manifests itself during conversations in which narratives or stories are told ... . Regardless of the subject under consideration or what people think they are talking about, they are always communicating about themselves" (78). Even in a television show as image conscious as Fox's Beverly Hills, 90210, McKinley found that young female viewers (re)fashioned their identities through "talk" about appearance, characterizations, and plot lines, rather than through image emulation (68-114). Lisa and the series in general provide shared semiotic referents for crafting selfnarratives that articulate one's own values and beliefs. Those who perform identity in Lisa's mode are no less enmeshed in the culture industries than those who perform in Bart's mode. Rather than simply co-opting images to code one's self, one integrates media images into her self-narratives. Though evolving self-narratives allow for some flexibility of identity, who one can be in this mode is limited to some extent by the structural limits of narrative, such as causality (Gergen $n$. pag.). By contemporary standards, the elements within the ideal narrative should build upon previous elements. However, as narrative itself changes through innovations such as hypertextual fiction, the possibility for viable fragmented and nonlinear self-narratives increases (Esders 77).

\section{(Re)Viewing Contemporary Identity}

So, what does all of this mean? After all, the question that prompted this study, "Who the hell am I?," stubbornly lingers. Though a 
definitive answer to that question continues to elude me, I am "coming to terms" with myself, which is another way of saying that I now have a language for describing my performance of identity. Like any language, this one entails both a vocabulary and a grammar, the rules of which are threefold. First, there is more than one mode for performing identity in a postmodern landscape. Much of the literature on postmodern identity treats it as a singular, alternative mode to modern identity (van Poecke). But an analysis of Bart, Homer, and Lisa Simpson indicates that such a dichotomy fails adequately to capture the full range of identity modes exercised by contemporary subjects. How one performs identity has to do with how one conceives of image and reality at/in a particular moment/space.

In the Bart-based mode, the modernist distinction between image and reality begins to erode, and the image deflects attention from the search for an external reality. For Bart, the notion of an autonomous self is feasible, but located in images that appear to have a life of their own. The images need not gesture outward, therefore, to do the work of identity. Bart Simpson and the Olsen twins continuously manufacture their sense of self through selective image appropriations, though one leans toward images of attitude and the other toward images of style. There is, for both, no substantial self that exists behind the images, as the images are the self. In this mode, "identity is . . . constituted theatrically through ... image construction" and is subject to constant reconstruction (Kellner 242).

A second mode announces the death of all reference; it is "the radical negation of the sign as value" (Baudrillard, Simulations 11) and with no interior and exterior the whole notion of the subject dissolves. Without referent, there is only obscenity - "a seeing without insight because there is no third dimension, no interior, narrative destination to be seen into or traveled toward" (Herron 24-25). This is the two-dimensional life of the cartoon, of Homer Simpson, for whom the media and information landscape is all there is. The transparency of the landscape, or its inability to signify, prevents the construction of an autonomous and coherent subject and allows only for the pleasure of consumption. "We say, 'Homer eats,' 'Homer drinks,' 'Homer belches,' when in reality there is nothing called 'Homer' beyond the eating, drinking, and belching. There is no being behind the doing. Homer just is the sum of his actions, and no more" (Conrad 66). In this mode, the subject evaporates and all social and political action becomes futile and absurd. 
In a third mode, embodied by Lisa, the image is not to be trusted in isolation. The static and two-dimensional image, unable to capture process, distorts essences. Since no single image (or, for that matter, compilation of independent images) can adequately convey an essence that is always in the process of becoming, the sign must be set in motion. Images are subsumed by narrative, which in turn creates relationships among signs that allow for growth, progress, and politics. A narrative-based identity does not eschew images; it simply alters what the image is asked to do. But Bart, Homer, and Lisa do not constitute the sum total of all identity modes today. For some, especially those who avoid media, the image may retain its full referential potential. It implies the existence of an external reality-a reality that can adequately and accurately be depicted by the image. Since this mode suggests a reality that is re-presentable, identity can be relatively innate, essential, and stable. One can be a Texan in the modernist sense to the extent that one has "faith" in the ability of an image to "stand in" for Texan-ness.

Second, how we conceptualize identity is wrought with ideology and politics. What counts and doesn't count as identity performance is implicated in relationships of power. Lisa suggests that the perspective that all postmodern identity is image-based is misguided and, according to Flax, "gender bound and biased" (52). Treating the antisubject stance represented by Homer Simpson, for instance, as the sole or even the dominant mode of postmodern identity, potentially silences women's voices "at the very moment that women (and other marginalized groups) for the first time in history are constituting themselves as empowered subjects" (Rosenau 52). Indeed, a similar danger may be inherent in the suggestion that image-based and narrative-based models of identity are exclusive. Here, scholars risk constructing and perpetuating binaries that imply hierarchies of value. Only by attending carefully to the texts of media culture and the multitude of ways that consumers view and use them can media scholars aid persons in experiencing their rhetorical environments more richly.

Third, the various modes for enacting identity today are not mutually exclusive; we move between them as psychological need and context dictate. Sometimes I perform my identity through appropriation by stealing shamelessly from Bart. The Simpsons T-shirt I occasionally don when teaching and the many Simpson toys-each in its pristine package-lining my office shelves furnish a frequent 
conversation piece for my colleagues, who often display unease at what they represent. Through Bart, I am able to code myself partly against the academy to which I have always had an uneasy relationship. Bart is, of course, not all there is to my identity or I would not be writing this article. I blend the image of Bart with other mediated images into a sort of identity pastiche. But I find that there are moments/spaces that I need to do more than just coopt an image. As an image of rebellion, Bart always stands against, never for anything (Conrad 75). Outside of the context of authority, Bart does nothing for me. My politics are (or at least I like to think they are) more complex than purely oppositional. I am a Marxist and a feminist, and these are aspects of my identity that I perform largely, as Lisa, through self-narrative. In my critical media studies class, I tell stories about my experiences with media texts, and those stories are negotiations of selfhood that testify to values and beliefs. However, my politics are exhausting at times, and it takes significant emotional energy to give them voice. So other times, I take a break from being me and just "watch" television. In these moments, there is only the indulgence of watching. Hence, Bart, Lisa, and Homer collectively furnish the images, stories, and pleasures that make and unmake me.

Months have passed since I began writing this article, and my Bart Simpson doll has been watching over me the entire time. I pick up the doll, intending to pull his cord, hoping that one of his catch phrases will inspire me as I write this conclusion. But as I cradle the doll in my hands, I notice for the first time that Bart's once bright blue clothing has faded from prolonged exposure to the sun, and I begin to wonder if Bart's time in the sun will soon be over, and if the show too will soon begin to fade. After twelve seasons, The Simpsons has already outlasted most television programs. In another year or so, the popularity of Bart and The Simpsons will wane, and Bart will no longer be able to serve me as he does now. Appropriating him will mark me as nostalgic, not oppositional. If I wish to continue to code myself as resistive, I will have to acquire new fragments, new images, and this leaves me wondering, "What's on tonight?"

\section{NOTES}

An earlier version of this article was presented at the 2001 Western States Communication Association annual convention, Coeur d'Alene, Idaho.

The author wishes to thank Greg Dickinson for his helpful comments on earlier drafts. 
1. "[The Simpsons] has been nominated for thirty-three Emmys and has won fifteen, as well as a Peabody Award" (Pinsky, "How Big” 34). In addition to its critical acclaim, the series is truly a global phenomenon, having been translated into twenty languages and airing in upwards of sixty countries (Swart).

2. Among the groups to criticize The Simpsons were the right-wing Media Research Center, which named it among the ten most biased shows of 1992, and the Catholic League for Religious and Civil Rights (Pinsky, "The Moral” 13-I).

3. Eight days after President Bush's remark on January 30, 1992, Bart responds in the episode "Stark Raving Dad” (\#7F24): “Hey, we're just like the Waltons. We're praying for the end of the depression, too." That night's episode, which originally aired September 19, 1991, was specially edited to include the response to the president.

4. The Simpsons are, of course, voiced by actors. But as Pinsky reminds, "the Simpsons' voices remain excellent actors, not stars. The relative absence of stars allows an astonishing kind of imaginative freedom even within the restraints of a rigid, mass-medium format" (“Creating” 17).

5. In the episode "Krusty Gets Busted" (\#7G12), Bart says of Krusty, "He's my idol. I've based my whole life on his teachings."

6. By the eighth season, sixty-one unique items of Krusty-related merchandise had appeared on The Simpsons. For a complete list, see Richmond and Coffman 208-09.

7. For a list of meta-references on The Simpsons, see http://www.snpp.com/guides/meta.html.

8. After Homer is vindicated of sexual harassment charges in the episode "Homer, Bad Man" (\#2F06), the tabloid TV show "Rock Bottom" prints a list of corrections at the end of their weekly episode. The list scrolls on the Simpsons' TV set much too fast for viewers of The Simpsons to read unless they employ stop frame technology on a VCR. Though many of the items on the list are nonsensical, the fourth, eighth, thirteenth, and thirty-third items are specifically addressed to the select individuals who taped the show and then watched it a frame at a time on their VCRs. Uncovering such "hidden" messages undoubtedly prompts feelings of pride, accomplishment, and belonging. The entire list follows:

- "Peoples' Choice Awards" is America's greatest honor.

- Styrofoam is not made from kittens.

- The UFO was a paper plate.

- The nerds on the Internet are not geeks.

- The word "cheese" is not funny in and of itself.

- The older Flanders boy is Todd, not Rod.

- Lyndon Johnson did not provide the voice of Yosemite Sam.

- If you are reading this, you have no life.

- Roy Rogers was not buried in his horse.

- The other UFO was an upside down salad spinner.

- Our universities are not "hotbeds" of anything.

- Mr. Dershowitz did not literally have four eyes.

- Our viewers are not pathetic sexless food tubes.

- Audrey Hepburn never weighed 400 pounds.

- The "Cheers" gang is not a real gang.

- Salt water does not chase the thirsties away.

- Licking an electrical outlet will not turn you into a Mighty Morphin Power Ranger.

- Cats do not eventually turn into dogs.

- Bullets do not bounce off of fat guys.

- Recycling does not deplete the ozone.

- Everything is $10 \%$ fruit juice.

- The flesh-eating virus does not hide in ice cream. 
- Janet Reno is evil.

- V8 juice is not $1 / 8$ gasoline.

- Ted Koppel is a robot.

- Women aren't from Venus and men aren't from Mars.

- Fleiss does floss.

- Quayle is familiar with common bathroom procedures.

- Bart is bad to the bone.

- Godfry Jones' wife is cheating on him.

- The Beatles haven't reunited to enter kick-boxing competitions.

- The "Bug" on your TV screen can see into your home.

- Everyone on TV is better than you.

- The people who are writing this have no life.

\section{Works Cited}

Barker, Chris. Cultural Studies: Theory and Practice. Thousand Oaks, CA: Sage Publications, 2000.

Baudrillard, Jean. Simulations. Trans. Paul Foss, Paul Patton, and Philip Beitchman. New York: Semiotext(e), 1983. ."The Masses: The Implosion of the Social in the Media." Media Studies: A Reader. Ed. Paul Marris and Sue Thornhman. New York: New York UP, 2000. 98-108.

Bianculli, David. "Hurray for 'Simpsons' Family Values! Underachieving Bart and His Kooky TV Clan Celebrate 10 Happily Dysfunctional Years." Daily News 13 Jan. 2000: 46.

_. Dictionary of Teleliteracy: Television's 500 Biggest Hits, Misses, and Events. New York: Continuum, 1996.

Billen, Andrew. "Groening Success." New Statesman 26 June 2000: 49-50.

Borrelli, Christopher. "Lisa Simpson: Queen of the $20^{\text {th }}$ Century." The Augusta Chronicle 19 Mar. 2001. Accessed on 17 May 2001 〈http://augustachronicle.com/stories/031901/fea_UE0089-4.shtml〉.

Bourdieu, Pierre. "The Biographical Illusion." Identity: A Reader. Ed. Paul du Gay, Jessica Evans, and Peter Redman. Thousand Oaks, CA: Sage Publications, 2000. 297-303.

Brummett, Barry. "Burkean Comedy and Tragedy, Illustrated in Reactions to the Arrest of John DeLorean." Central States Speech Journal 35 (1984): 217-27.

Rhetoric in Popular Culture. New York: St. Martin's Press, 1994. 
Campbell, Richard, and Rosanne Freed. "We Know It When We See It': Postmodernism and Television." Television Quarterly 26 (1993): 75-87.

Conrad, Mark T. "Thus Spake Bart: On Nietzsche and the Virtues of Being Bad.” The Simpsons and Philosophy: The D'oh! of Homer. Ed. William Irwin, Mark T. Conrad, and Aeon J. Skoble. Chicago: Open Court, 2001. 59-77.

Corliss, Richard. "The Cartoon Character Bart Simpson." TIME 8 June 1998: 204-05.

Crook, Stephen, Jan Pakulski, and Malcolm Waters. Postmodernization: Change in Advanced Society. New York: Sage, 1992.

Croteau, David, and William Hoynes. Media/Society: Industries, Images, and Audiences. 2nd ed. Thousand Oaks, CA: Pine Forge Press, 2000.

Elm, Joanna. "Are the Simpsons America's TV Family of the '90s?" TV Guide 17 Mar. 1990: 7-8.

Erickson, Hal. Television Cartoon Shows: An Illustrated Encyclopedia, 1949 Through 1993. Jefferson, NC: McFarland and Company, Inc., 1995.

Esders, Karin. "(The) Playing Author: Narrativity and Identity in Literature and Interactive Media." Simulacrum America: The USA and the Popular Media. Ed. Elisabeth Kraus and Carolin Auer. Camden House, 2000. 75-83.

Featherstone, Mike. Consumer Culture and Postmodernism. Newbury Park, CA: Sage, 1991.

Fish, Stanley. "Interpreting the Variorum." Critical Inquiry 2 (1976): $465-85$.

Flax, Jane. Thinking Fragments: Psychoanalysis, Feminism, and Postmodernism in the Contemporary West. Berkeley: U of California P, 1990.

Gergen, Kenneth J. "Narrative, Moral Identity and Historical Consciousness: A Social Constructivist Account." Draft copy for an edited volume on narrative and historical consciousness, University of Bielefeld, forthcoming. 22 May 2001. 〈http:// www.swarthmore.edu/SocSci/kgergen1/text3.html $>$.

Giddens, Anthony. Modernity and Self-Identity. Stanford, CA: Stanford UP, 1991.

Glass, James M. "Multiplicity, Identity and the Horrors of Selfhood: Failures in the Postmodern Position." Political Psychology 14 (1993): 255-78. 
Gomez-Pena, Guillermo, and Roberto Sifuentes. Temple of Confessions: Mexican Beasts and Living Santos. New York: powerHouse Books, 1996.

Halwani, Raja. "Homer and Aristotle." The Simpsons and Philosophy: The D'ob! of Homer. Ed. William Irwin, Mark T. Conrad, and Aeon J. Skoble. Chicago: Open Court, 2001. 7-24.

Harvey, David. The Condition of Postmodernity: An Enquiry into the Origins of Cultural Change. Cambridge, MA: Blackwell, 1990.

Heim, Michael. The Metaphysics of Virtual Reality. New York: Oxford UP, 1993.

Herron, Jerry. "Homer Simpson's Eyes and the Culture of Late Nostalgia." Representations 43 (1993): 1-26.

Huff, Richard. "TV Males 'Violent': Kids, Boys Don't See Selves in Small-Screen Guys.” Daily News 1 Oct. 1999: 130.

Jenkins, Henry. “Do You Enjoy Making the Rest of Us Feel Stupid?': alt.tv.twinpeaks, the Trickster Author, and Viewer Mastery." Full of Secrets: Critical Approaches to Twin Peaks. Ed. David Lavery. Detroit: Wayne State UP, 1995. 51-69.

Kanaley, Reid. "The Simpsons in Cyberspace." Philadelphia Inquirer 7 Dec. 1994: F1-2.

Kellner, Douglas. Media Culture: Cultural Studies, Identity and Politics Between the Modern and Postmodern. New York: Routledge, 1995.

Leary, Timothy. "The Cyberpunk: The Individual as Reality Pilot." Cyberreader. Ed. Victor J. Vitanza. 2nd ed. Boston: Allyn and Bacon, 1999. 364-72.

McKinley, E. Graham. Beverly Hills, 90210: Television, Gender, and Identity. Philadelphia: U of Pennsylvania P, 1997.

McNeil, Alex. Total Television: The Comprehensive Guide to Programming from 1948 to the Present. $4^{\text {th }}$ ed. New York: Penguin Books, 1996.

Mink, Eric. "Last But Not Least, the Best of the '90s: The Tube's Second Golden Age." Daily News 31 Dec. 1999: 102-03.

Morley, David, and Kevin Robins. "Spaces of Identity: Communications Technologies and the Reconfiguration of Europe." Screen 30 (1989): 10-34.

- Spaces of Identity: Global Media, Electronic Landscapes and Cultural Boundaries. New York: Routledge, 1995.

O'Sullivan, Tim, John Hartley, Danny Saunders, Martin Montgomery, and John Fiske. Key Concepts in Communication and Cultural Studies. 2nd ed. New York: Routledge, 1994. 
Ott, Brian, and Cameron Walter. "Intertextuality: Interpretive Practice and Textual Strategy." Critical Studies in Media Communication 17 (2000): 429-46.

Owen, Rob. Gen X TV: The Brady Bunch to Melrose Place. Syracuse, NY: Syracuse UP, 1997.

Pinsky, Mark I. "The Moral Life and TV's 'The Simpsons." The Denver Post 22 Aug. 1999. 13-I, 14-I. 34.

Pinsky, Robert. "Creating the 'Real,' in Bright Yellow and Blue." New York Times 5 Nov. 2000: 12, 17.

Poniewozik, James. "The Best TV Show Ever.” TIME 31 Dec. 1999: 73.

Poster, Mark. The Second Media Age. Cambridge, MA: Cambridge UP, 1995.

Rebeck, Victoria A. "Recognizing Ourselves in the Simpsons." The Christian Century 27 June 1990: 622.

Richmond, Ray, and Antonia Coffman, eds. The Simpsons: A Complete Guide to Our Favorite Family. New York: HarperPerennial, 1997.

Rosenau, Pauline Marie. Post-Modernism and the Social Sciences: Insights, Inroads, and Intrusions. Princeton, NJ: Princeton UP, 1992.

Rushkoff, Douglas. Playing the Future: How Kids' Culture Can Teach Us to Thrive in an Age of Chaos. New York: HarperCollins, 1996.

Sands, Roberta G. "The Elusiveness of Identity in Social Work Practice with Women: A Postmodern Feminist Perspective." Clinical Social Work Journal 24 (1996): 167-86.

Shales, Tom. "Return of 'The Simpsons': Still the Best on the Block." Washington Post 30 Sept. 1993: B1, B10.

Snierson, Dan. "100 greatest entertainers: The Simpsons." Entertainment Weekly 5 Nov. 1999.

Swart, Sharon. "World Gets a Kick out of Twisted U.S. Family." Variety 23 Apr. 1998.

Turkle, Sherry. Life on the Screen: Identity in the Age of the Internet. New York: Touchstone, 1997.

van Poecke, Luc. "Media Culture and Identity Formation in the Light of Postmodern Invisible Socialization: From Modernity to Postmodernity." Communications 21 (1996): 183-98.

Vitanza, Victor J. Cyberreader. 2nd ed. Boston: Allyn and Bacon, 1999. 
Zehme, Bill. "The Only Real People on TV: At Home with the Simpsons." Rolling Stone 28 June 1990: 40-47.

Zoglin, Richard. "Home Is Where the Venom Is." TIME 16 Apr. 1990: 85 .

Brian L. Ott is assistant professor of media studies at Colorado State University. 